\section{CASE STUDY: "BEING EXPERT EASILY AND QUICKLY" APPLICATION OF UP-TO-DATE INFORMATION TECHNOLOGY INTO THE STANDARD CREATION PROCESS}

\section{Tomáš Vejlupek, Martin Másílko}

\section{Abstract}

The subject of this case study is an innovative methodology for working with information allowing to quickly gain a high level of expertise in any area of human activities. The methodology is presented as an example of creating a new hempcrete standard and it is easily transferable to other areas (for example the medicinal research area).

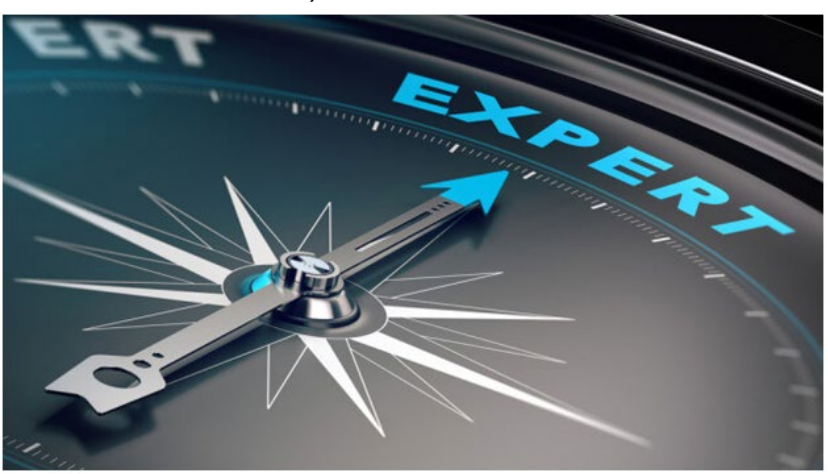

Figure 1 - Illustrative

\section{Motivation}

We have been cooperating with ASTM International since the year 2017. ASTM International, formerly known as American Society for Testing and Materials, is an international standards organization that develops and publishes voluntary consensus technical

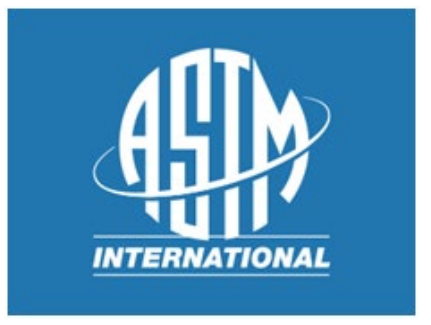
standards for a wide range of materials, products, systems, and services. These standards are then used by companies throughout the world.

We apply information technology to solve the problem of increasing the level of expertise of standardization specialists. We have found a way to do this by creating an information environment in which the specialists can quickly gain the necessary expertise. As a demonstration field, ASTM has chosen the topic of hempcrete.

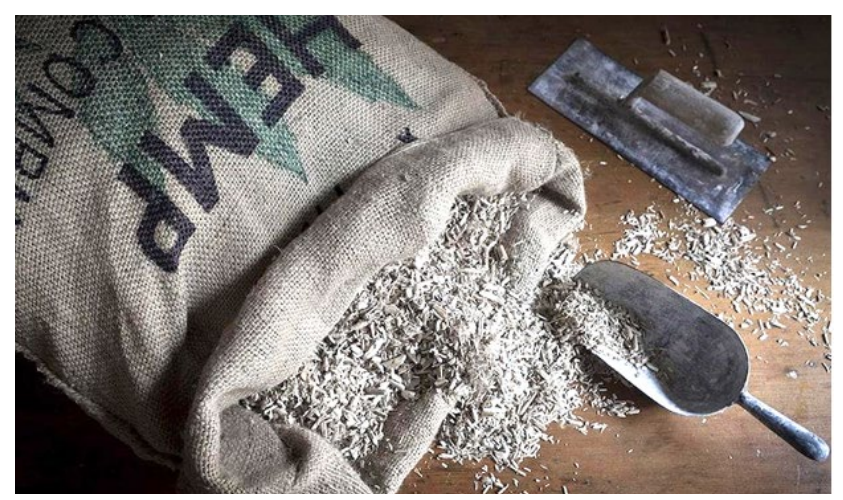

Figure 2 - Illustrative

\section{Expertise Creation Process}

We followed these stages:

- Basic topic analysis

- Existing sources search

- Indexing

- Advanced topic analysis

- Standard synthesis

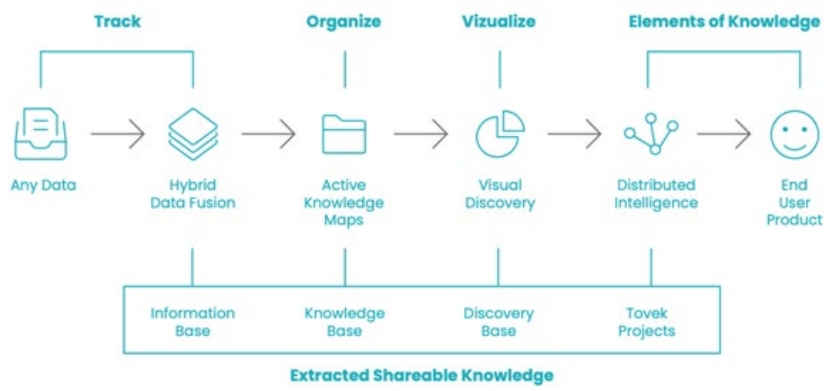

Figure 3 - Methodology Stages

\section{Basic Topic Analysis}

An analyst had no knowledge related to hempcrete. Using simple internet search an initial topic mind map was created.

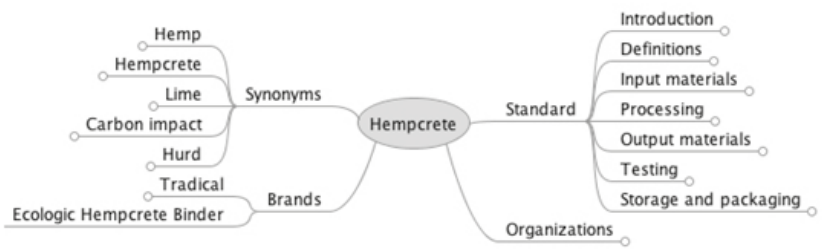

Figure 4 - Initial MindMap

The initial mind map served as a baseline for the project and finding seeding webs. A list of seeding webs was created by using Google advanced search operators.

\section{Existing Sources Search}

The list of seeding webs was used by an application that automatically downloads websites from the Internet. We made local copies of the seeding websites and also several referenced links (further websites) - recursively. Only texts were downloaded for further indexing purposes. This way we made a collection of $26.000+$ documents that contained many hempcrete related data.

Additionally, we searched manually for ResearchGate, Patents and downloaded further $200+$ documents.

\section{Indexing}

We used the TOVEK indexing engine to create a hempcrete information base. Information bases are an analytical index allowing unified fulltext search using advanced Tovek Query Language.

The Tovek index includes nor only keywords but also automatically extracted entities based on rules, machine learning and statistics for automatic content analysis enabling to discover groups of words representing important topics.

Tovek index helps to navigate in the content and discover hidden structures to find the appropriate information. 


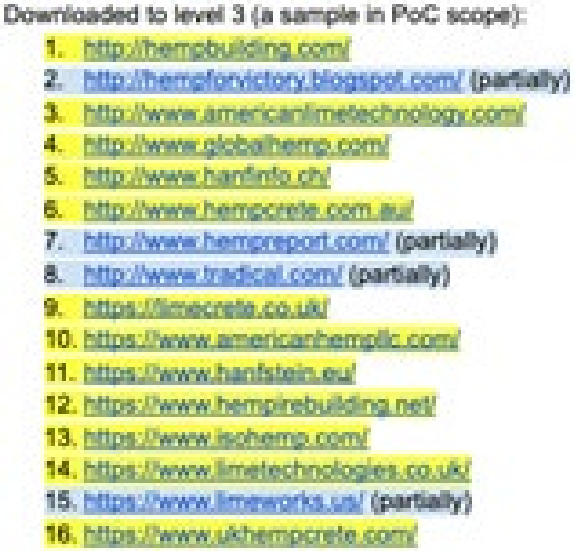

To Be Downloaded (out of PoC scope)

hitto llwwwehemstrade cal

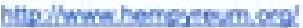

hitplilwweindestiotherrene;

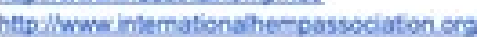

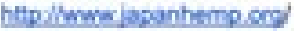

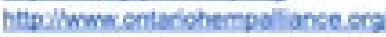

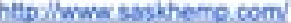

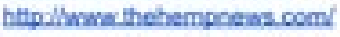

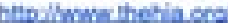

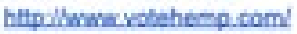

holos $/ 420$ intel coml

hitps iboheso wondpress $\mathrm{com}$

helpsilleatoabisindustodsumalcom/

httosilleins om

hitios:lereenbrildingcanada ca:

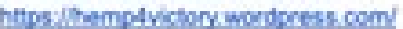

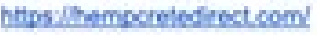

Figure 5 - Seeding Web Pages

\section{Advanced Topic Analysis}

TOVEK tools enable a wide range of methods to identify the key pieces of knowledge and supporting evidence. The advanced topic analysis is aimed at the formation of complex concepts, so called Active Knowledge Maps, which are necessary to create a standard.

Related structures for advanced search were created using these tools. Although the analyst had no previous experience with the hempcrete topic, it was possible to find "the hidden knowledge" in the downloaded data within several hours. The knowledge trees were quickly created and expanded, selecting only relevant information from the data "ocean".

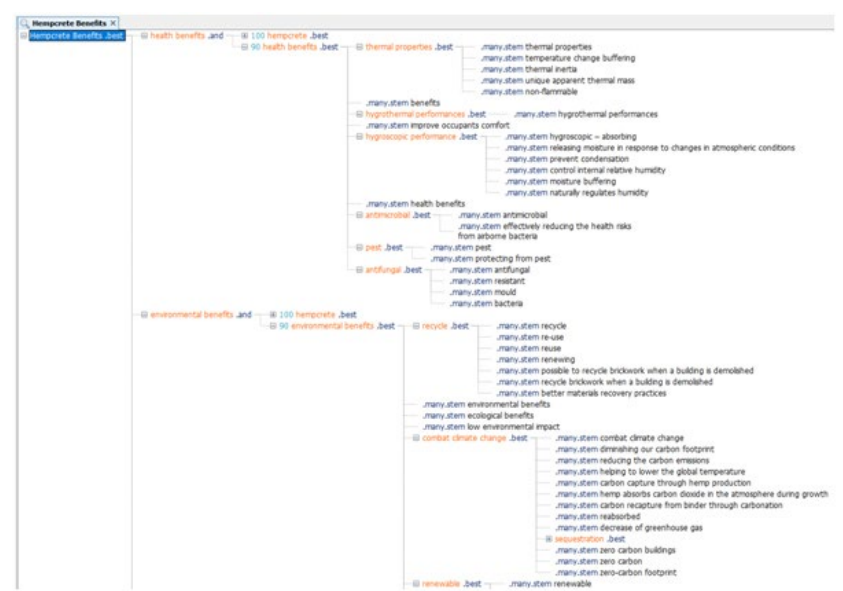

\section{Standard Synthesis}

New structures of a target standard were created, using TOVEK Visual Knowledge Discovery features. You can easily extract selected facts from search results, drag and drop and link them in the emerging structure of the standard represented by the diagram. The diagram is indexed again so that you not only can search in the content but also visualise the structure in different contexts.

TOVEK tools then automatically generate standard drafts, which need to be shaped by a human to the final wording.

\section{Achievement}

In a short time frame we were able to do the following:

- Compile a collection of texts about hempcrete,

- Create a full-text search engine for all the sources found at the stage of the existing sources search,

- Create a knowledge base about hempcrete,

- Analyze information on hempcrete and synthesize a complex concept,

- Create a standard draft (for chosen examples),

- Create a new standard for ASTM, which could be verified by ASTM members.

\section{Conclusion}

The project methodology is transferable to any other area. It is possible to prepare an expert - state of the art - text on any topic, while deeply understanding how to use Internet search tools, local indexing and how to perform content analysis and synthesis.

The methodology has only one limitation, it doesn't create completely new processes or methods.It only improves existing knowledge.

The methodology developed and presented allows the transfer of the best possible known practices into new structures. It might find new knowledge and related topics to experts performing the tasks. The most labor-intense parts of the process are the advanced analysis of information and new structures synthesis - using human skills and experience.

All the steps delivered within the case-study can be fully or semi automated. The automation allows keeping all the data and related structures up-to-date and performing updates.

The case-study allows you to estimate the level of expertise which can be gained using the methodology and the indexing system. It is possible to quickly achieve a high level of expertise in any area of human activities.

\section{About}

TOVEK is a Czech independent company producing software tools for data processing to minimize the gap between information and useful information. For almost three decades, TOVEK has been developing cutting-edge software for analytical search and processing information from various unstructured and structured data sources.

Hidden Data Technologies is a brand of DC Czech, Ltd. which was founded in 1993.

Hidden Data Technologie specializes in mining and processing large amounts of data to find hidden information and knowledge. It employs cutting-edge data science and artificial intelligence using automatic structured data extraction from unstructured data sources based on complex semantic rules. 


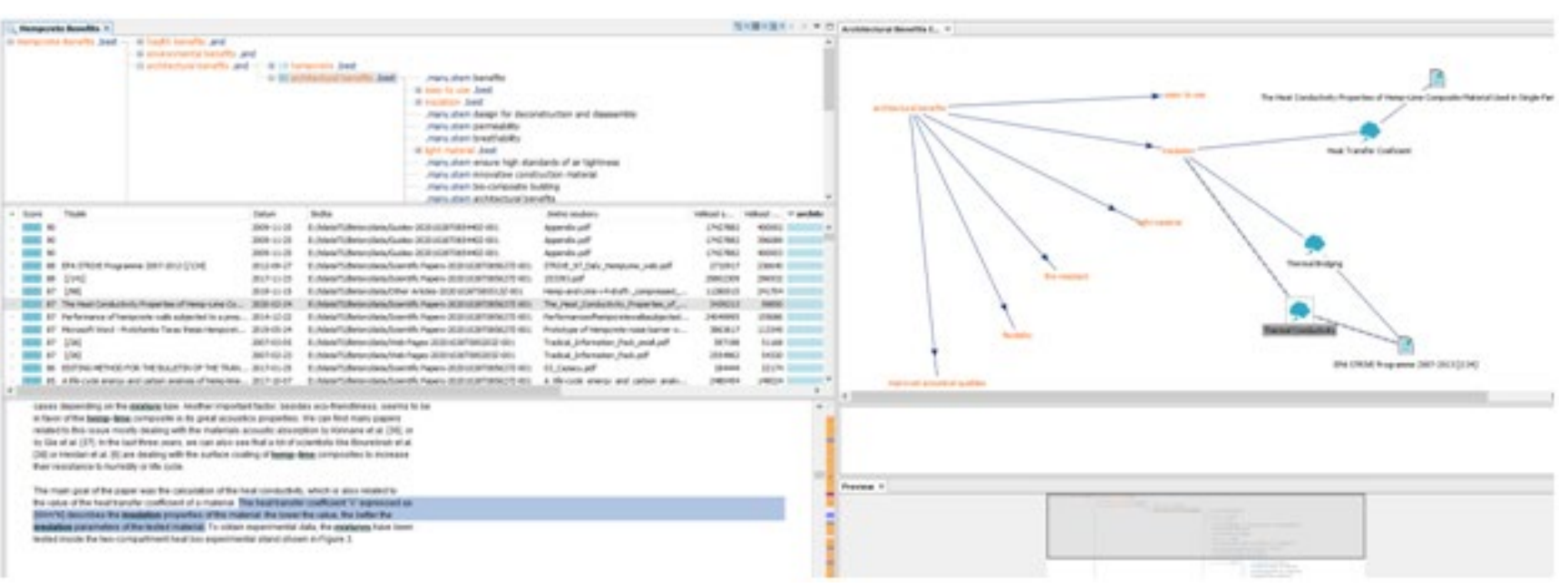

Figure 7 - Standard Synthesis

\section{Architectural Benefits}

insolusen

\section{ien Pronder Cieflicient}

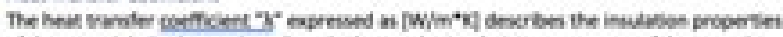
of the muberiak the bestr the value, the better the indilabon parametert of the teited maters:

\section{Thermul Bidery}

Wemp Lime thermal conductively values ave generally waperior to concrete and wabject to

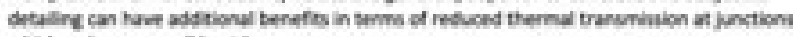
which redices everil nex lew.

\section{Servil = MHouane}

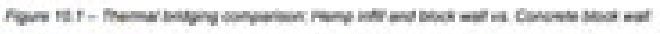

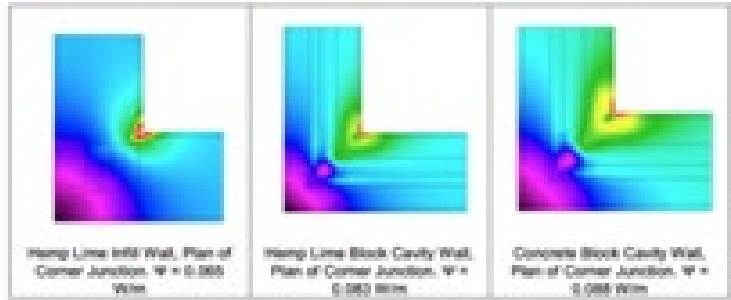

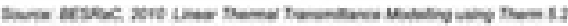

\section{Thernul Conductsty}

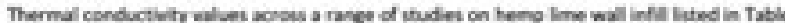

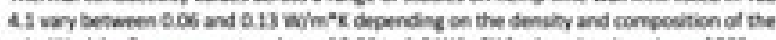

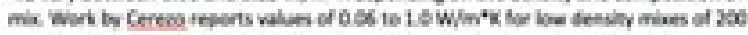

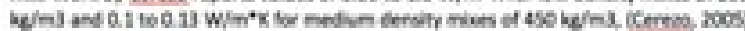

Figure 8 - Standard Export and Manual Completion

\section{Masual - Final Standard Paragraphs Synthesis}

\section{Architectural Benefits}

Insulation

Hempcrete provides excellent benefits for construction in terms of preventing thermal brideing and low thermal conductivity.

The heat transfer coefficient ${ }^{*}$ "expressed as $\left[W / m^{*} \mathrm{X}\right]$ describes the insulation properties of a material. The lower $\lambda^{*}$ value, the better the inulation parameters are.

Hempcrete thermal conductivity values are generally uperior to concrete and reducing thermal tranamission at junctions, which reduces overall heat loss.

Hempcrete thermal conductivity values vary between 0.06 and $0.13 \mathrm{~W} / \mathrm{m}^{*} \mathrm{~K}$ depending on the density and composition of the mix $=$ values of 0.06 to $1.0 \mathrm{~W} / \mathrm{m}^{4} \mathrm{~K}$ for low density mixes of $200 \mathrm{~kg} / \mathrm{m}^{2}$ and 0.1 to $0.13 \mathrm{~W} / \mathrm{m}^{*} \mathrm{~K}$ for medium density mixes of $450 \mathrm{~kg} / \mathrm{m}^{3}$.

Thermal conductivity values for hemp lime masonry are generally influenced by whether blocks have thermal or structural purposes, and their overall max and compaction methods ffor example for hemp lime cement block samples, that were machine vibrated and compacted, record a value of $0.34 \mathrm{~W} / \mathrm{m}^{4} \mathrm{~K}$, or hemp lime block that were spray applied reported values ranging from 0.179 to $0.543 \mathrm{~W} / \mathrm{m}^{*} \mathrm{~K}$.

\section{Contact}

Ing. Tomáš Vejlupek

vejlupek@tovek.cz

TOVEK, spol. s r.o.

Chrudimská 1418/2, Praha 3

www.tovek.cz

Martin Másílko, MBA

martin@masilko.cz

DC Czech, s. r. o.

Konviktská 291/24, Staré Město, Praha 1 